\title{
Chapter 9 \\ Intergenerational Reproduction of Distinctive Cultural Capital: A Study of University Education Obtained Abroad and at Home
}

\author{
Martin D. Munk
}

\section{Introduction}

Cultural and social reproduction strategies are no longer limited to nation states but now operate across borders. A number of scholars have noted that investments in foreign elite education have become increasingly attractive (e.g., Wagner 2007), but supporting evidence is limited due to a lack of suitable data. An increasing number of students are enrolling in and completing university programmes, including in Denmark; however access is characterised by social selection, which particularly implies horizontal differentiation (Munk and Thomsen 2018). This social selection could affect the willingness to invest in education abroad. I suggest that the acquisition of this type of distinctive cultural capital abroad is viewed as an intergenerational reproduction strategy that supplements the portfolio of other strategies. Thus, I investigate whether migrants who graduate from elite universities abroad constitute a socially selected group. Prior research provides ample evidence of the effect of family background on the likelihood of obtaining higher education in domestic universities, and previous studies have demonstrated that family background is still a vital condition in educational attainment, especially with regard to elite education. However, whether social origin also increases the probability of obtaining higher education abroad remains unresolved. Therefore, I examine how family background affects the likelihood of obtaining a degree from an elite or non-elite university abroad compared to obtaining a university education at home, with no university as the reference category. This design is unique in the literature on international students because this line of research has lacked a comparison group in the home country to assess whether there is an effect

\footnotetext{
Martin D. Munk ( $\square)$

Department of Political Science, Aalborg University, Copenhagen, Denmark

e-mail: mdm@dps.aau.dk
} 
that differs from social selection in domestic universities. The tool that currently defines elite and non-elite universities is university ranking lists, inspired by the study published by Wendy Espeland and Michael Sauder in the American Journal of Sociology in 2007. The merging of survey and register data has made it possible to compare migrants with non-migrants with regard to a set of common covariates. The combination of high-quality register data containing information on parental background and a weighted sample of emigrants makes it feasible to answer these questions. I restrict the sample to Danes who emigrated in the period between 1987 and 2002 and who had lived abroad for at least 5 years.

Only a few previous studies link the literature on educational or cultural reproduction to the literature on global higher education and migration. Munk (2009) analyses the acquisition of informational capital in prestigious foreign educational institutions as measured by Erasmus student mobility. He reveals that students from the upper and upper-middle social classes (measured by parental occupation) are more likely than students from other social classes to pursue transnational investments, although students from the middle and working classes have entered the competition. Other studies, such as Jasso (2011), link migration and admission into educational institutions. This gap in the literature is unsurprising because the vast majority of the existing social stratification literature was developed at a time when very few people studied abroad. In this chapter, I find that having highly privileged parents - often with abundant cultural capital and transnational orientations - increases the likelihood of obtaining a university education at home and abroad.

\section{Theory}

In the theory of reproduction strategies, Pierre Bourdieu posits that families possessing a high stock of capital strategically invest in credentials that have the highest distinctive and transferrable value (Bourdieu 1996) either at home or abroad. Because the venue for cultural reproduction is for the most part the horizontal dimension of the university system and because student mobility across borders has been increasing (Börjesson 2017), I focus on universities, both at home and abroad. Admission requirements for elite universities are demanding and studying abroad can be costly; thus it is likely that individuals from affluent and socially privileged families are particularly attracted to universities that are highly ranked on international ranking lists (Espeland and Sauder 2007; Sauder and Espeland 2009; see also Börjesson 2017).

Most studies of the reproduction of higher education analyse the patterns and intergenerational correlations within nation states as most students previously remained in their home country. Studies of social stratification and theories of social reproduction were mainly developed at a time when the key terms in theories of reproduction-education and social class-were relatively stable (Brown and 
Lauder 2009). A central contribution in this area of research is the theory of cultural and social reproduction by Bourdieu, who developed his theories in a national context by focusing on the social conditions of exclusion from and selection into the educational system. In particular, he studied distinct Grandes Ecoles, elite schools at the top of the French university hierarchy (Bourdieu 1996; Munk 2009). Access to these elite schools is understood to be highly unequal, which ultimately results in unequal outcomes (Alboury and Wanecq 2003). In the US case, Karabel (2005) focused on the strong link between an elitist origin and admission to the Big Three: Harvard, Yale, and Princeton. According to Bourdieu (1996), families maintain their social position or existence through a multi-dimensional set of reproduction strategies. The classic example of an education strategy is the conversion of economic capital to cultural capital by families who are alert to the need for their children to obtain an education that will result in potentially advantageous pathways and prestige. This strategy is especially utilised by the upper class, but to a growing extent, it is also used by the upper-middle classes and other groups who are aware of the importance of education. However, Bourdieu focused on elite schools at home and did not directly examine the acquisition of distinctive education abroad and emigration as such. His long-standing collaborator Abdelmalek Sayad $(1991,2004)$ studied strategies of emigration and immigration, but from the perspective of a poor country (Algeria) rather than emigration from a European country to study in other Western countries.

Different aspects of transnational strategies are highlighted in Wagner (1998, 2007), Munk (2009), Brown and Lauder (2009), and Soehl and Waldinger (2012). Most of these studies do not relate to social origin or compare outcomes in national settings. However, the tendency of international student mobility to be socially selective is noted in empirical studies (e.g., Netz and Finger 2016). Both economic and sociological approaches suggest that children with socially advantaged origins invest more in international education, especially distinctive elite education. Consequently, they become part of the Zones of Prestige (Collins 2001) to distinguish themselves and maximise their opportunities, both abroad and at home. Following Bourdieu, the term cultural capital refers to various forms of knowledge, educational credentials, language, dispositions, and materialised advantages that provide social recognition (Bourdieu 1984). In this chapter, I consider cultural capital transmitted from parental education and language and cultural capital that can be attained by a migrant. The term cultural capital has been used primarily in national contexts. Nonetheless, in the global space of higher education institutions (Börjesson 2017) which has a particular distribution of distinctive cultural capital that is typically displayed and highlighted by the world rankings of these institutions (Espeland and Sauder 2007) - education is increasingly acquired or applied abroad. Cultural capital can therefore become relevant for transnational aspirations and strategies to expand the stock of capital or to gain distinctive cultural capital abroad, sometimes conceptualised as cosmopolitan capital (cf. Weenink 2008), which involves the same dimensions as the aforementioned definition of cultural capital. What I want to stress with regard to distinctive cultural capital acquired abroad is the fact that it goes 
beyond the national educational field; emigrants are investing in capital outside of their national context.

However, there is a potential caveat: the majority of the migrants I analyse have prior experience of being abroad with their parents; thus, it seems appropriate to consider the degree to which they are truly bound to a national context. They certainly have a level of experience with other countries, which implies that some of these individuals are actually positioned between a national and a transnational context. Furthermore, many of them probably belong to what other scholars conceptualise as transnational families (or cosmopolitan families). These individuals are prone to study abroad because they have been exposed to international environments during their upbringing, and they already possess good language skills and have an international circle of friends (Palloni et al. 2001).

From the perspective of cultural capital, obtaining a university degree abroad functions as a cultural reproduction strategy. This is the case especially for individuals who went abroad with their parents during their upbringing and have therefore adopted transnational orientations and accumulated distinctive cultural capital abroad. Alternately, they may simply have become more disposed to invest in cultural capital abroad, making the choice of a university programme abroad quite natural (Weenink 2008: 1092). Therefore, I present three scenarios to interpret investment strategies in education abroad and at home to explain and understand people's endeavours to obtain a degree abroad, sometimes with the ambition of finding a transnational position. The formation of transnational elites occurs especially in the United States (Kim 2016) and the United Kingdom. Capital acquired in the Zones of Prestige can, in turn, contribute to the creation of a transnational class or power elite (Weenink 2008; Brown and Lauder 2009; Caroll 2010). However, I do not consider transnational positions in this chapter.

One scenario comprises a tradition in internationally minded families holding cultural capital that makes them more likely to take advantage of educational opportunities abroad. The idea is that children from the most privileged social classes spend time in foreign countries to acquire the skills, qualifications, and knowledge required to maintain the family's position nationally or perhaps even transnationally (Johnson et al. 2011). In this sense, tradition latently prescribes that the new generations of the privileged classes go abroad to maintain the familys' social status. Therefore, the aim of studying abroad is not only to obtain valuable knowledge but also to obtain a distinctive asset needed to maintain the family position. At the same time, children in these families may be prone to migrate because their parents migrated as well, and they therefore have stronger dispositions towards out-migration.

In another and newer scenario, children from upper-middle-class families obtain elite education abroad as a new means of obtaining distinctive capital because increased enrolment in national universities has reduced the social advantage that national education used to provide (Wagner 2007). Under these new conditions, with an increasingly competitive environment, it is argued that upper-middle and upper-class students and their families must find new ways to reproduce their social advantage through investments in overseas education (Brooks and Waters 
2009: 1086-1087). This novel tendency raises the question of the evolution of the intergenerational reproduction of higher education. Therefore, I compare two types of university education obtained abroad with two types of university education obtained in a national setting.

A third scenario presents an even newer tendency in which children pursue social mobility (a compensatory strategy). Specifically, students apply to universities abroad and acquire distinctive cultural capital that can potentially compensate for a lack of cultural capital in the home country to gain occupational prestige or simply to climb the social ladder at home or abroad. Some researchers suggest that upward social mobility, rather than social reproduction, is the driving force behind some parents' propensity to provide their children with cosmopolitan capital (Weenink 2008: 1103). According to this reasoning, attending international programmes is related to social ambitions more than to social reproduction. A study by Favell (2008) suggests that mobility may be more likely to be pursued by less privileged people than their peers from more privileged backgrounds. Less privileged young people may gamble with spatial mobility in their education and careers abroad to improve their social mobility opportunities, which are otherwise blocked at home (Brooks and Waters 2011). In particular, it may be that non-elite institutions abroad recruit from classes with primarily economic capital as a means to improve their social position.

\section{Data}

I analyse education abroad using two surveys of Danes who emigrated in the period between 1987 and 2002. These surveys were organised by Martin D. Munk and Panu Poutvaara in the Danes Abroad project and were conducted by Statistics Denmark. ${ }^{1}$

The survey data are from Danish citizens who emigrated from Denmark in 1987, 1988, 1992, 1993, 1997, 1998, 2001 or 2002 and who were between 18 and 59 years of age when they emigrated. For the eight selected years, emigrants are split into those who were still abroad and those who were again residing in Denmark according to the migration register as of December 31, 2007.

A total of 17,309 individuals emigrated in the selected emigration years and had not returned to Denmark. A major challenge in reaching people living abroad is that there are no data on their addresses in the Danish population register. To address this problem, Statistics Denmark first contacted parents or siblings who were residing in Denmark. They found contact information for a relative in Denmark for $54 \%$ of the cases or 9415 emigrants. Seven percent of these people did not provide contact information for their emigrated relative. The primary reasons were that the relative was no longer in contact with the emigrated person or the relative

\footnotetext{
${ }^{1}$ I thank Mette Foged for excellent research assistance. Financial support from the Danish Council for Independent Research Fund Social Sciences (FSE) is gratefully acknowledged.
} 
refused to participate. This left a group of 8749 emigrants with available contact information. Those with only an address and telephone number were contacted and asked to provide their e-mail address. Final validation of the collected emails showed that 6984 emails were valid, and only people for whom email addresses were available were contacted. The data collection was performed using a webbased questionnaire. After several tests, the final questionnaire was sent to the 6984 emigrants in mid-June 2008, followed by three rounds of reminders to those who had not answered. When the data collection was closed, 4260 emigrants $\left(\mathrm{N}_{1}\right)$ had answered the questionnaire.

For returned migrants, the sampling process was simpler. These migrants were stratified into six groups. Because shorter migration spells constitute the majority of migrations from Denmark, we undersample short durations abroad such that they do not constitute most of the final survey data. ${ }^{2}$ The resulting selected population contained 5700 return migrants, and contact information was obtained for 4600 of these return migrants. Data collection for return migrants started towards the end of September 2008. The return migrants 4600 received a letter with information on the survey, the website address and a password. Those who did not complete the web questionnaire were later contacted by phone, if was possible. The interviews lasted 45 minutes on average. A total of $70 \%$ of the 3065 replies $\left(\mathrm{N}_{2}\right)$ were received through the Internet. Similar to the 'stayers', the response rate for 'returners' was very high compared to similar surveys, at $67 \%$.

We focus on individuals who had either stayed abroad at the time the surveys were conducted in 2008 or had returned to their home country after being abroad for more than 5 years. In the surveys, respondents were asked whether they had studied abroad; if so, a number of questions related to their studies were asked.

This section describes the data sources and sample restrictions and how we measure and quantify international elite education. Survey data on emigrants and return migrants are used and combined with population register data. The survey data include information on whether the respondent had obtained a degree abroad and if so, where. The application of register data allows for the construction of a proper comparison between groups of people who did not attend universities and people who had enrolled in Danish universities.

\section{Combining Survey and Register Data}

After excluding emigrants to Greenland and the Faroe Islands, the sample included 4126 respondents who had not returned to Denmark by 2007 and 2597 respondents who had returned to Denmark by 2007. In total, 983 migrants had obtained

\footnotetext{
${ }^{2}$ The applied sampling weights were $2 \%, 4 \%, 4 \%, 12 \%, 20 \%$ and $60 \%$ from the group with the shortest to the longest duration abroad (up to 6 months, 6-12 months, 1-3 years, 3-5 years, 5-10 years and 10 or more years abroad, respectively).
} 
Table 9.1 Survey observations

\begin{tabular}{l|c|c|l|l|c|c}
\hline \multirow{2}{*}{ Duration } & Returners & \multicolumn{2}{l|}{ Stayers } & \multicolumn{2}{l}{ Total } \\
\cline { 2 - 8 } & Degree abroad & All & Degree abroad & All & Degree abroad & All \\
\hline 0 to 6 months & 4 & 112 & & & 4 & 112 \\
\hline 6 to 12 months & 22 & 433 & & & 22 & 433 \\
\hline 1 to 3 years & 22 & 429 & & & 22 & 429 \\
\hline 3 to 5 years & 38 & 349 & & & 38 & 349 \\
\hline 5 to 10 years & 61 & 507 & 768 & 3857 & 829 & 4364 \\
10 years or longer & 147 & 1830 & 768 & 3857 & 915 & 5687 \\
\hline Number of observations & & & & & &
\end{tabular}

university degrees abroad. The analysis is restricted to people who at the time of their emigration were between 18 and 39 years of age at the time of their emigration as almost all respondents who had obtained a degree abroad belonged to this age group. Only 16 older respondents were deleted.

Table 9.1 shows the number of respondents and the number who had obtained a degree abroad according to the duration of their stay abroad. Ultimately, $N$ target was 829 people who had obtained a university education abroad. Of this group, 768 were still abroad, and 61 had returned in 2007.

The same restrictions that were applied to the survey respondents were applied to the remaining register data to form a comparison group of those who had attended Danish universities and those who had not attended university at all.

\section{Measuring Elite Education}

For all migrants who had obtained a degree abroad, detailed information is available on the specific country, year, degree and university, and this information is applied in the statistical analysis. I divide universities into elite and nonelite institutions using the detailed information and international ranking lists. Although international ranking lists are not an objective measure of the best and most prestigious foreign universities, they are likely to be indicative of the perceptions held by Danish migrants. Moreover, some authors argues that these lists currently dominate global university systems (Sauder and Espeland 2009; Kauppi and Erkkilä 2011). The ranking lists are QS-Times' Higher Education's Annual World University Ranking 2004 (http://www.timeshighereducation.co.uk/hybrid. asp?typeCode=153) and the Financial Times' Ranking of the best MBA schools in the world in 2004 (see http://rankings.ft.com/businessschoolrankings/global-mbarankings-2004). QS-Times' rankings are based on academic peer reviews, citations per faculty member, faculty-student ratio, global employer review, international study ratio, and international faculty ratio, in that order. An alternative is the Shanghai Ranking List, which relies on the number of Nobel Prize recipients among 
employees and students and the number of publications in journals such as Science and Nature. Both sets of rankings confirm the reputations of the leading American and British universities, such as Harvard, Stanford, Yale, Berkeley, MIT, Cambridge, and Oxford. Some of the elite universities abroad most frequently represented in the data are the University of London, Oslo University, the University of Oxford, Stockholm University, Lund University, University College London, College of Europe, London Business School, the University of Cambridge, the London School of Economics, King's College, Columbia University, and the University of Chicago. The elite universities at home are the University of Copenhagen, Aarhus University, and the Technical University of Denmark.

\section{Method}

In the statistical analysis, I compare Danes who had obtained a degree abroad to Danes with no university education and Danes who had attended universities in Denmark. The survey data provide information on whether respondents had obtained a university degree abroad at the time they answered the survey. Educational attainment for non-migrants in 2007 is taken from Danish register data. In this way, it is possible to divide our population into five groups: no university education, non-elite university in Denmark, elite university in Denmark, non-elite university abroad and elite university abroad. This section explains the weighting scheme and the multinomial logistic model with weighted data used to analyse the five distinct types of educational attainment.

\section{Weighting Scheme}

Respondents are made representative of migrants in the survey years by inverse probability weights. ${ }^{3}$ The probability of being in the survey is estimated separately for men and women and for returners and stayers to account for differences in response behaviour and differences with respect to how the data were collected. The probability models are kept simple to avoid making the results overly sensitive when small subgroups are analysed. All models control for emigration year, age at emigration and country groups, which are defined as English-speaking countries,

\footnotetext{
${ }^{3}$ Inverse probability weighting is a statistical technique for calculating statistics standardised to a population that is different from the population in which the data were collected. Study designs with a disparate sampling population and population of target inference (target population) are common in application (cf. Robins et al. 1994). Here, the applied weights are the inverse probabilities of being in the survey. In inverse probability-weighted data (IPW data), parameter estimates are calculated based on the idea that each observation represents a number of individuals in the underlying population.
} 
other Nordic countries, the rest of Europe, and the rest of the world. As explained previously, respondents who were still abroad were contacted through their parents. The analysis displays significant selection at the parental education level for this group; therefore, parental education levels are included in the probability models for stayers. Parental education is not significant for returned migrants, which makes sense given the differences in how the data were gathered. On the other hand, given that the migrants' education level is not controlled in the simple probability models used and education level is known to often play a role in response propensities, it is perhaps surprising that parental education is not significant for returners as a proxy for the migrants' own education level. Most emigrants who study abroad are young people who have yet to complete their education. Therefore, there is no control for educational level. To account for different sampling weights in the two duration groups (5-10 years and 10 years or more), a duration group dummy is included in the probability models for returned migrants. One returned respondent represents on average 9.3 emigrants, and one stayer represents 4 emigrants who stayed abroad.

\section{Model}

The model setup is a weighted maximum-likelihood multinomial logit specification, implying that the individual likelihood contributions are weighted by the inverse sampling probabilities. The calculation of inverse sampling probabilities is made possible by linking the survey respondents to the underlying population from which they are sampled. Robust standard errors are calculated to account for the uncertainty introduced by the fact that respondents with education abroad are represented by survey data. A multinomial logit model is a natural choice because our education groups cannot be ordered. In addition, these models are chosen such that the results can be compared with other results on access to universities (e.g., Munk and Thomsen 2018). The results are likely to reflect a two-dimensional capital hierarchy beyond the traditional distinction between academic and non-academic education. To obtain disjunctive groups, all individuals who emigrated in the survey years with university education in Denmark are excluded.

The reported model estimates are relative risk ratios (RRRs), which is a generalisation of odds ratios to multinomial models. These RRRs are provided to convey a sense of the net effects rather than the marginal effects. All covariates are included as dummy variables. Thus, the RRR is the ratio of the relative probability of the outcome in question (compared to the reference outcome) when the dummy variable changes from zero to one. An RRR of 2.5 means that if the dummy variable equals one, the likelihood of the outcome in question compared to the reference outcome is 2.5 times more likely than if the dummy variable equals zero. More generally, an RRR $<1$ implies that the dummy variable in question reduces the likelihood of the outcome, while an RRR $>1$ implies a higher likelihood of the outcome relative to the reference outcome of no university education. 


\section{Cultural Capital and Social Capital Abroad}

In this section, I present facts about respondents' pre-emigration situation with regard to their families, their own experiences living abroad, and their friends living abroad. To measure a crucial dimension of cultural capital abroad, I specifically scrutinise three key items. The first item is whether, the respondents had lived abroad with their parents before emigrating. The second item is whether the respondents' parents had lived or studied abroad, and the third item is whether the respondents' parents spoke English. These items are similar to those applied by Weenink (2008), who measures parents' international behaviour by their frequency of business trips abroad; their work-related use of oral and written English; whether they hosted foreign guests at home; whether they visited foreign friends; and whether they read foreign books and newspapers. The results are reported separately for men and women and for elite and non-elite education given that I expect a gender difference.

Table 9.2 reports the degree of cultural and social capital the respondents' parents and graduates possessed distributed by whether the respondents had acquired an elite or non-elite university degree abroad. Unsurprisingly, the findings show that the number of English-speaking parents is higher among elite university graduates. Additionally, the likelihood of being elite university alumni is typically higher if the respondents' parents had worked or studied abroad. A slightly higher fraction of men from non-elite universities had lived abroad with their parents than had men from elite universities, while the opposite holds for women. Generally, those from elite universities more frequently have friends or relatives in the country to which they emigrate; this is the case for almost four out of ten men and for more than half

Table 9.2 Indicators of cultural capital and social capital abroad held by graduates and parents

\begin{tabular}{|c|c|c|c|c|c|}
\hline & \multicolumn{2}{|l|}{ Men } & \multicolumn{2}{|l|}{ Women } \\
\hline & & Non-elite & Elite & Non-elite & Elite \\
\hline \multicolumn{2}{|c|}{ Had lived with parents abroad } & 9.3 & 8.2 & 7.7 & 10.9 \\
\hline \multicolumn{2}{|c|}{$\begin{array}{l}\text { Had friends or relatives in the destination country } \\
\text { before emigrating }\end{array}$} & 34.0 & 38.8 & 41.7 & 54.4 \\
\hline \multicolumn{2}{|c|}{$\begin{array}{l}\text { Had friends or relatives in the destination country } \\
\text { before emigrating, first time emigrants }\end{array}$} & 32.4 & 44.4 & 31.5 & 60.7 \\
\hline \multirow[t]{4}{*}{ Mother } & Speaks English & 63.4 & 64.6 & 65.1 & 71.7 \\
\hline & Had studied abroad & 13.9 & 18.4 & 10.6 & 13.0 \\
\hline & Had worked abroad & 25.8 & 27.2 & 29.1 & 37.7 \\
\hline & Had worked or studied abroad & 32.5 & 36.1 & 32.6 & 39.7 \\
\hline \multirow[t]{4}{*}{ Father } & Speaks English & 64.4 & 75.7 & 66.7 & 73.2 \\
\hline & Had studied abroad & 15.5 & 17.7 & 14.3 & 13.0 \\
\hline & Had worked abroad & 38.1 & 40.8 & 36.3 & 41.3 \\
\hline & Had worked or studied abroad & 42.8 & 48.3 & 40.3 & 43.5 \\
\hline \multicolumn{2}{|c|}{ Number of observations } & 194 & 147 & 350 & 138 \\
\hline
\end{tabular}

Source: Survey data

Note: Column percentages 
of the women. For non-elite university students, the situation is less striking: this is the case for only one-third of the men and four out of ten women.

In summary, the above results indicate that respondents who study abroad tend to have a significant stock of social capital, including an international circle of friends and relatives. In particular, women with more social capital abroad are more inclined to study at elite universities.

In addition to these factors, men are more often motivated by academic quality than women. Likewise, those who study at elite universities are more often motivated by academic quality than those who study at non-elite universities. Nearly half of the men and one-quarter of the women who obtain an elite university education abroad make the choice in part because, based on their evaluation, the foreign university is academically better. Additionally, two out of five men who obtain an elite education abroad favour valuable labour market skills, and approximately the same percentage favour prestige, while one-third cite better job opportunities abroad (Munk et al. 2011).

Respondents who studied in the US or UK stated more often than other respondents, that the university they attended was more prestigious and offered a higher academic level than universities in their home country. This pattern is especially pronounced for women. This result supports the Zones of Prestige thesis proposed by Collins (2001), which suggests that students are attracted to zones in specific countries partially because of prestige but also because of the perceived higher quality of the institutions. The study by Munk (2009) explains that the attraction is also driven by favourable academic capital.

\section{Cultural Reproduction}

In this section, I examine intergenerational cultural reproduction. First, I determine the proportion of men and women who earn a degree from abroad. The survey data show that $43 \%$ of men and $28 \%$ of women earned a degree from elite institutions abroad. When respondents in 2008 were asked to state their current highest level of education, $31 \%$ reported a bachelor's degree, $40 \%$ reported a master's degree, $20 \%$ reported a $\mathrm{PhD}$ or equivalent, and $9 \%$ reported an MBA. The data show that $76 \%$ of respondents have only one degree from abroad, $20 \%$ have two degrees and the remainder have three degrees, except for four persons who have four degrees from abroad.

Second, I analyse five outcomes in the same regression analysis and restrict the analysis to respondents for whom there is information on the education of both parents. This restriction is natural because in the analysis I focus on the intergenerational transmission of cultural capital. If the educational level of at least one parent is missing, there is a risk of misclassification of the highest parental education. The migrants' own education is measured by the survey data for migrants and the register data for non-migrants. Table 9.3 shows the distribution of parental education for the five aforementioned educational groups. Comparing the first three 
columns shows that parental education is strongly correlated with the likelihood of obtaining a non-elite or elite university education in Denmark. In particular, the fraction of those with university-educated mothers is eight to 11 times larger among women with university education at home than among to those with no university education. The distribution of parental educational levels for migrants who obtain a non-elite university education from abroad is similar to the distribution of parental educational levels for individuals with a non-elite university education from Denmark. Respondents who obtain an elite university education abroad have slightly better educated parents than respondents who obtain an elite university education in Denmark (and from non-elite universities abroad); this is the case particularly for women. It is striking that almost one-fifth of the women who attend elite institutions abroad have a mother with a university education, and one-fourth have a university-educated father. For men with an elite education abroad, one-tenth of their mothers and one-third of their fathers had obtained a university education. This pattern is found for generations for which only 5-6\% of fathers and 1-2\% of mothers obtained a university education. In summary, this means that both women and men who earn an elite degree abroad or at home have extremely well-educated families and hence a high degree of cultural capital, even compared to people who obtain a university degree at home.

With regard to elite education abroad, fathers appear to be role models for men and mothers appear to be role models for women. In fact, the analysis shows that the educational level of the parent of the same gender plays a substantial role in the outcome of the decision of whether to study abroad. The fraction of mothers with a university education is 9-12 percentage points higher for women who obtain an elite education abroad than for women who obtain an elite or non-elite university education in Denmark or a non-elite university education abroad. The same results apply for men with respect to their fathers' highest education.

In Tables 9.4 and 9.5, I present multinomial models of the effects of birth cohort, parental education and history of living abroad before the age of 18 on the likelihood of obtaining a university education at home or abroad. Note that multinomial logistic regression models should stand up to the independence of irrelevant alternatives (IIA) assumption, but the feasibility of IIA tests is disputed (Long and Freese 2006: 243-246). Dow and Endersby (2004) posit that estimating substitution patterns is often hypothetical, so the model is an approximation (Train 2009). Therefore, I describe a preference structure in the choice of universities without making causal claims based on the models. The purpose of the current study is mainly to study reproduction patterns that are not typically revealed in these types of studies (see Munk and Thomsen (2018) for a similar argument).

The statistical analysis confirms the social and gender differences found in Table 9.3. Overall, I find that family educational background strongly affects the likelihood of obtaining a university degree, for both men and women. The level of parental education increases the likelihood of obtaining an elite university degree both at home and abroad, most clearly for women. The distribution of parental education among those who obtain a non-elite education abroad does not differ from the distribution among those who obtain a non-elite university education in 


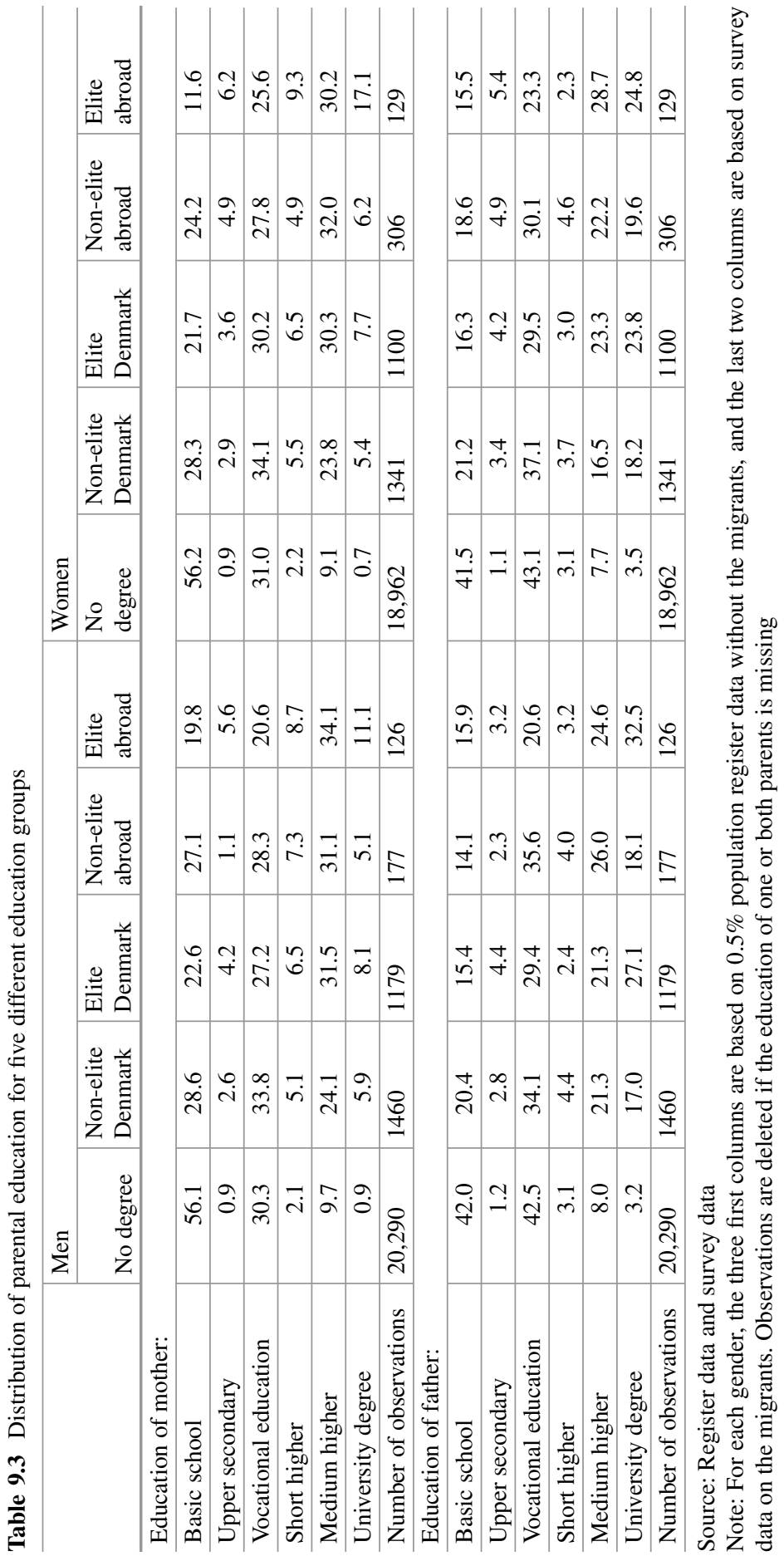




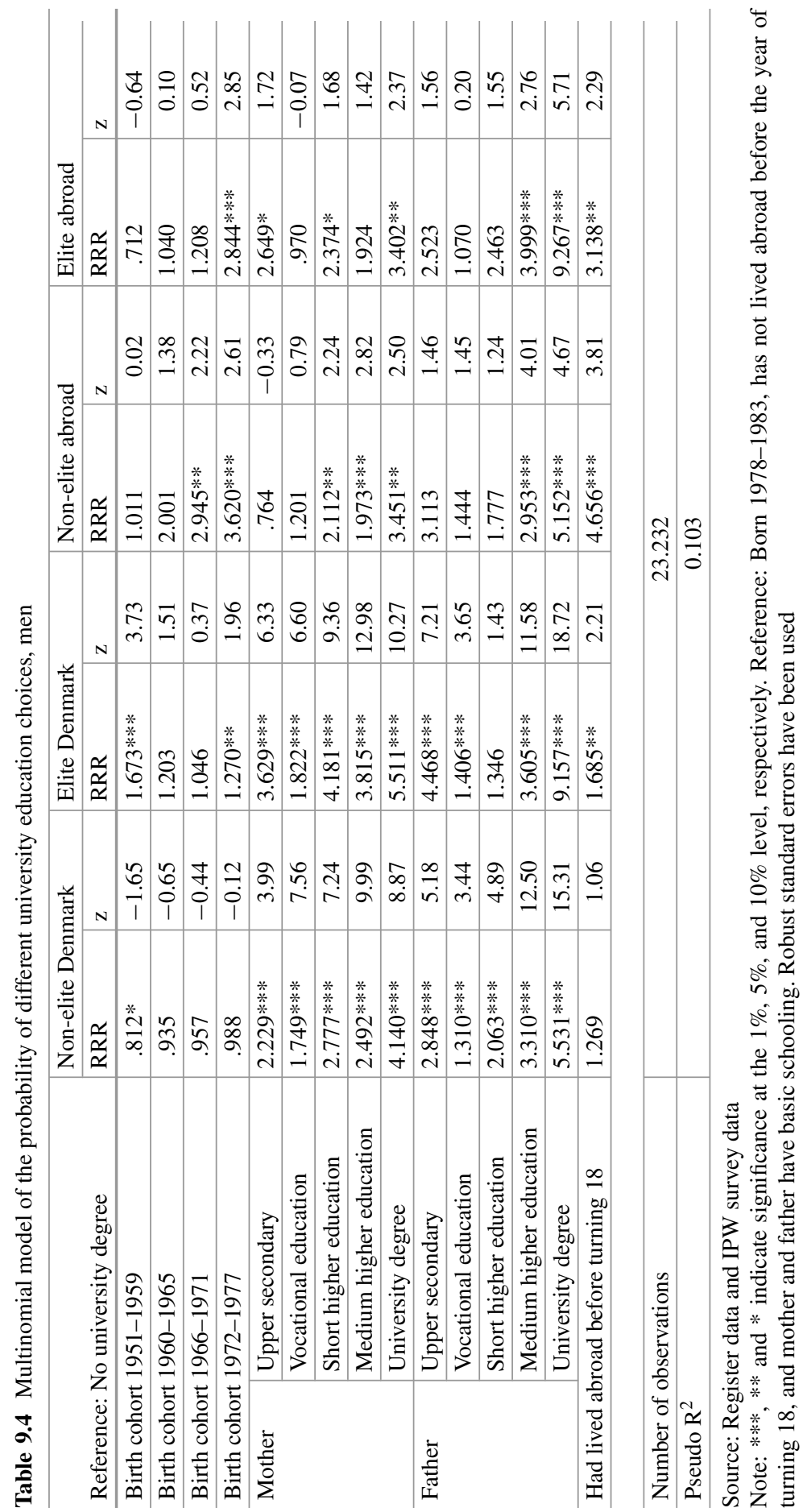




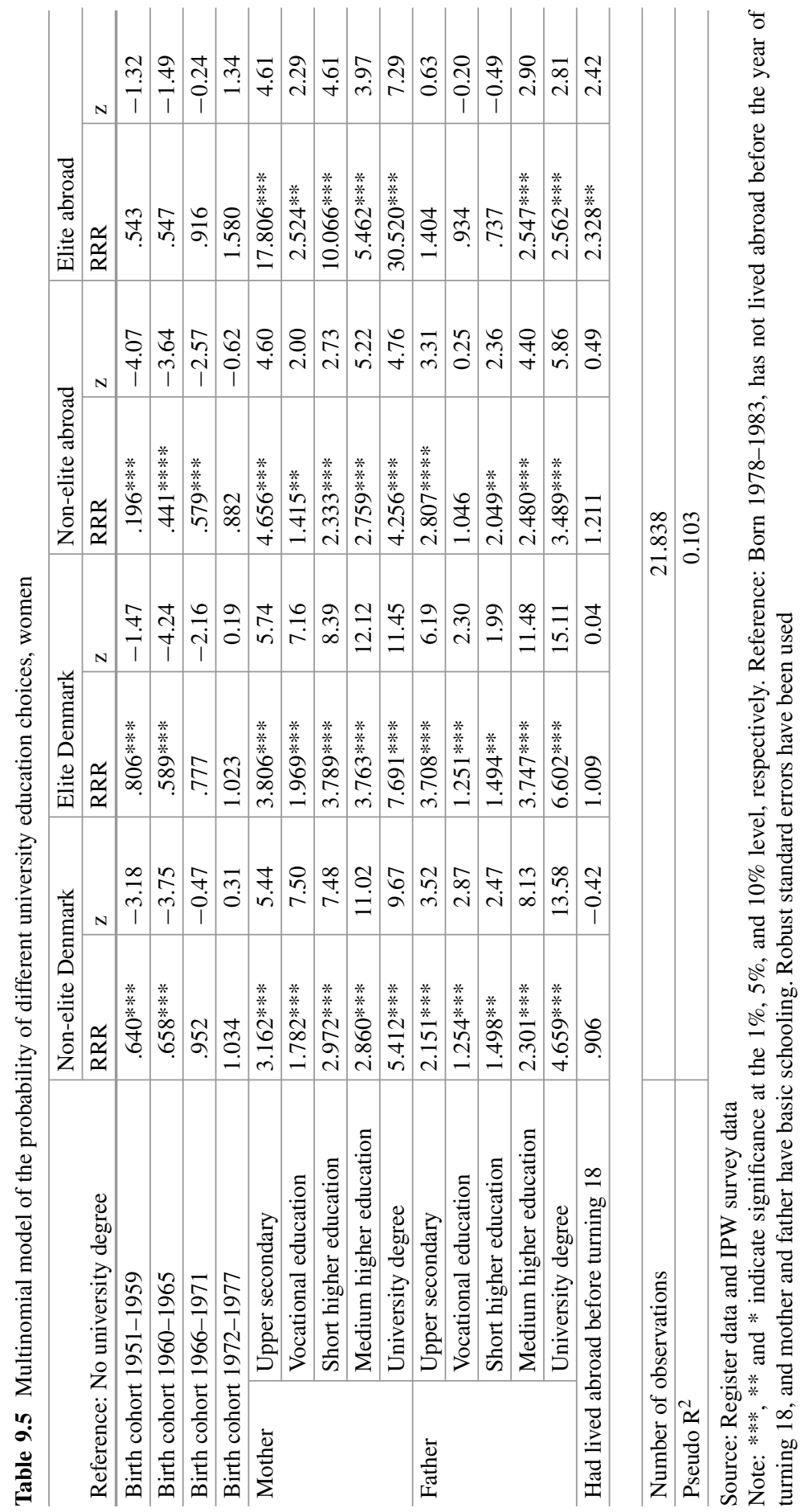


Denmark. Mothers seem to matter more for women and fathers seem to matter more for men in the decision of whether to obtain a university education. If the parent of the same gender has a university education, the likelihood of a respondent obtaining an elite education abroad increases strikingly, especially for women. This result is in line with previous research on nation states. Earlier studies have found that noblesse and wealthy families are reproduced through the mother's family (Schijf et al. 2004).

Both men and women who live abroad before the age of 18 are more than twice as likely to obtain an elite education abroad than those who do not, all else being equal. Men who live abroad before the age of 18 are almost five times more likely to obtain a non-elite university education abroad in comparison with men without experience living abroad in their early lives. Among women, no statistically significant effect on the likelihood of obtaining a non-elite education is found. Having lived abroad is generally associated with a higher probability of obtaining a university education abroad for men, whereas for women, only those with an elite education are statistically significantly different from the reference group with respect to early international experience. Therefore, women require transnational aspirations from their family to go abroad to obtain an elite degree. Some educational mobility is observed. (The analysis yields similar results when parental occupation are included).

The results are qualitatively similar if I use a stricter definition of elite education in which a university is required to be included in the ranking lists in both 2004 and 2005 to be defined as an elite university. The social selection of elite education abroad is consistent with the idea that investment in internationally recognised higher education is predominantly an applied strategy in upper-class elite families (measured by university parents) as well as in upper-middle-class families (measured by medium higher education (college) parents). Hence, intergenerational cultural reproduction as understood from national studies also operates in the transnational arena. Here, it should be noted that the evolution of transnational elite strategies for education does not imply that a strictly national elite reproduction process has ceased to exist as we also observe in the analysis. The vast majority of university graduates never study outside national (or even local) institutions (approximately one-third of the men who earn a degree abroad also earn a degree from home). Thus, the Zones of Prestige, where the space of elite universities leads to investments in distinctive cultural capital, should be perceived as an important supplement to, rather than a substitute for, nationally oriented strategies of reproduction.

I conduct a sensitivity analysis of the parameter estimates with respect to three alternative ways of tightening the definition of elite. The first alternative requires that the university is included in the ranking list for two consecutive years. The second alternative requires inclusion among the top 100 instead of the top 200 universities. Finally, MBA schools are omitted. The first modification tests the sensitivity of the results of small changes in the list from year to year since universities that shift in and out of the bottom of the list are omitted. The second modification tightens the definition of elite by moving the cut-off point up, while the 
last modification investigates the sensitivity with respect to categorising the MBA schools. Individuals recruited to top 100 universities and to universities compared to those recruited to MBA schools, are more often selected in terms of parental education. Hence, selection in terms of parental background is stronger when elite is defined more narrowly, but top 200 inclusion is chosen as the preferred definition considering the number of observations.

\section{Discussion and Conclusion}

Overall, I find that children with highly privileged parents are much more likely to seek an elite education abroad than children with less educated parents. In particular, children of upper-class parents with university degrees are much more likely to attend a higher-ranked university either at home or abroad.

The effect of parental background is much stronger with regard to obtaining an elite education abroad than with regard to obtaining a non-elite education abroad or a non-elite university education at home. These effects are slightly larger than those for elite universities at home, especially for women. Additionally, close to 40-50\% of individuals pursuing an elite education abroad have parents who have studied or worked abroad. Hence, the intergenerational transmission of distinctive cultural capital operates within transnationally oriented families. The role of the father's education is more vital for men; likewise, the role of the mother's education is more vital for women, especially among women pursuing an elite education. These relations are probably rooted in socialisation patterns in families. In this study, I find a remarkably strong association between parental characteristics and the likelihood of obtaining a university degree abroad. Furthermore, the finding that the likelihood of attending an elite university is much higher for individuals from families with parents who themselves are university graduates is in line with other scholars' findings on national dynamics. One study shows that social origin has a clear, direct and persistent impact on the choice of a selective elite university education in the United States. One reason for this finding is that people from privileged social backgrounds are able to more easily adapt to the necessary behaviours and competencies: "Being attuned to the changing circumstances, the privileged devote considerable effort to cultivating their own stock of currencies required for entry into lucrative positions" (Alon 2009: 750).

I find that for women, having a mother with a university degree increases the probability of obtaining an elite university education abroad more than it increases the probability of obtaining an elite university education in Denmark and much more than it increases the probability of obtaining a non-elite university education abroad or at home. In addition, individuals who live abroad before the age of 18 are more likely to obtain a university education abroad than those who do not, even after controlling for parental education (and occupation, not presented), especially for men. Parents who live with their children abroad or send them abroad to study or work seem to stimulate their children to adopt an international habitus in their 
early life, which becomes evident through good language skills, strong international networks, and probably the motivation to acquire valuable skills and prestige. In fact, children from this type of family tend to pursue a trajectory in which the academic quality is considered to be higher.

The reason for this behaviour could be that early-life socialisation stems from a conscious strategy in families with high levels of cultural capital with possible transnational aspirations, or it could simply be that children from families who are used to the global scene are likely to pursue foreign education because it is easier and more natural for them than for respondents who lack experience in international environments. The transmission process seems to be that parents' pass on cultural capital and some social capital to their children, including a willingness and ability to look beyond borders that can eventually become relevant for transnational prospects. This argument is in line with the study by Soehl and Waldinger (2012), who contend that "socialisation in the parental household is powerful, transmitting distinct home country competencies, loyalties and ties, but not a coherent package of transnationalism." In this chapter, I document the reproduction of educational privileges in a transnational context, thus partly rejecting the idea that investments in distinctive cultural capital abroad merely imply social mobility. Although I find some evidence of social mobility, the overall pattern shows that elite education is highly restricted in terms of parental background.

A number of sociologists currently suggest that a global system of higher education, or even a global space (not a global field, as noted by Börjesson 2017), has emerged in which the most prestigious universities recruit elite students globally. Brown and Lauder (2009: 136) state that educational credentials, which were once mostly acquired nationally, now have a significant global dimension. The division between elite and non-elite institutions is noted by Bourdieu (1996) in a study of higher education in a national context. He distinguishes between very selective to through elite schools (grande porte) and less selective entrance to other universities (petite porte). His findings show a connection between graduating from elite universities and obtaining major posts within society as well as a connection between graduating from less selective universities and obtaining minor posts within society, but still at the higher end of the social ladder. This pattern is termed structural homology.

This chapter specifically contributes to the literature by showing that educational reproduction and mobility can work through the global space of university institutions. In particular, it shows that young people from a privileged background are more likely to attend elite universities abroad and to see most of the world as their field of study and work place. This phenomenon may have nothing to do with the increased access to universities in Denmark but rather may be related to the fact that families with abundant cultural capital accumulate more distinctive cultural capital in terms of the finest academic qualifications from prestigious universities at home and abroad, primarily in the United States and the United Kingdom. These findings support the Zones of Prestige hypothesis, which Randall Collins (2001, see also Karabel 2005) introduced as a way to understand the major attraction of students to elite universities in the US. Conclusively, in the case of migrants attending elite 
universities, it is not simply a matter of pursuing transnational strategies abroad but rather a question of accumulating distinctive cultural capital.

\section{References}

Alboury, V., \& Wanecq, T. (2003). Les inégalités sociales d'accès aux Grandes Écoles. Économie et Statistique, 361, 27-47.

Alon, S. (2009). The evolution of class inequality in higher education: Competition, exclusion, and adaptation. American Sociological Review, 74(5), 731-755.

Bourdieu, P. (1984[1979]). Distinction: A social critique of the judgement of taste. Cambridge, MA: Harvard University Press.

Bourdieu, P. (1989). La noblesse d'état, Grandes Ecoles et esprit de corps. Paris: Les Editions de Minuit (State Nobility, Cambridge: Polity Press 1996).

Brooks, R., \& Waters, J. (2009). A second chance at 'success': UK students and global circuits of higher education. Sociology, 43(6), 1085-1102.

Brooks, R., \& Waters, J. (2011). Student mobilities, migration and the internationalization of higher education. Basingstoke: Palgrave Macmillan.

Brown, P., \& Lauder, H. (2009). Globalization, international educations, and the formation of a transnational class? Yearbook of the National Society for the Study of Education, 108(2), 130147.

Börjesson, M. (2017). The global space of international students in 2010. Journal of Ethnic and Migration Studies, 43(8), 1256-1275.

Carroll, W. K. (2010). The making of a transnational capitalist class: Corporate power in the 21st century. London: Zed Books.

Collins, R. (2001). Civilisations as zones of prestige and social contact. International Sociology, 16(3), 421-437.

Dow, J. K., \& Endersby, J. W. (2004). Multinomial probit and multinomial logit: A comparison of choice models for voting research. Electoral Studies, 23(1), 107-122.

Espeland, W. N., \& Sauder, M. (2007). Rankings and reactivity: How public measures recreate social worlds. American Journal of Sociology, 113(1), 1-40.

Favell, A. (2008). Eurostars and Eurocities: Free movement and mobility in an integrating Europe. Oxford: Blackwell.

Jasso, G. (2011). Migration and stratification. Social Science Research, 40(5), 1292-1326.

Johnson, C. H., Sabean, D. W., Teuscher, S., \& Trivellato, F. (2011). Transregional and transnational families in Europe and beyond: Experiences since the middle ages. New York: Berghahn Books.

Karabel, J. (2005). The chosen. In The hidden history of admission and exclusion at Harvard, Yale, and Princeton. Boston: Mariner Books, Houghton Mifflin Company.

Kauppi, N., \& Erkkilä, T. (2011). The struggle over global higher education: Actors, institutions, and practices. International Political Sociology, 5(3), 314-326.

Kim, J. (2016). Global cultural capital and global positional competition: International graduate students' transnational occupational trajectories. British Journal of Sociology of Education, $37(1), 30-50$.

Long, J. S., \& Freese, J. (2006). Regression models for categorical dependent variables using Stata. College Station: StataCorp.

Munk, M. D. (2009). Transnational investments in informational capital. A comparative study of Denmark, France, and Sweden. Acta Sociologica, 52(1), 5-23.

Munk, M. D., Foged, M., \& Mulvad, A. M. (2011). Familiers kosmopolitiske uddannelsesstrategier - Et spørgsmål om migration og investering i distinktiv kapital (Families' cosmopolitan 
educational strategies, a question of migration and investment in distinctive capital). Dansk Sociologi, 22(3), 31-58.

Munk, M. D., \& Thomsen, J. P. (2018). Horizontal stratification in access to Danish university Programmes. Acta Sociologica, 61(1), 198-210.

Netz, N., \& Finger, C. (2016). New horizontal inequalities in German higher education? Social selectivity of studying abroad between 1991 and 2012. Sociology of Education, 89(2), 79-98.

Palloni, A., Massey, D. S., Ceballos, M., Espinosa, K., \& Spittel, M. (2001). Social capital and international migration: A test using information on family networks. American Journal of Sociology, 106(5), 1262-1298.

Robins, J. M., Rotnitzky, A., \& Zhao, L. P. (1994). Estimation of regression coefficients when some regressors are not always observed. Journal of the American Statistical Association, 89(427), 846-866.

Sauder, M., \& Espeland, W. N. (2009). The discipline of rankings: Tight coupling and organizational change. American Sociological Review, 74(1), 63-82.

Sayad, A. (1991). L'immigration ou les paradoxes de l'altérité. Bruxelles: De Boeck \& Lancier.

Sayad, A. (2004). The suffering of the immigrant. Cambridge: Polity Press.

Schijf, H., Dronkers, J., \& van den Broeke-George, J. (2004). Recruitment of members of Dutch noble and high-bourgeois families to elite positions in the 20th century. Social Science Information, 43(3), 435-475.

Soehl, T., \& Waldinger, R. (2012). Inheriting the homeland? Intergenerational transmission of cross-border ties in migrant families. American Journal of Sociology, 118(3), 778-813.

Train, K. E. (2009). Discrete choice methods with simulation. Cambridge, UK: University Press.

Wagner, A. C. (1998). Les nouvelles élites de la mondialisation. Une immigration doree en France. Paris: PUF.

Wagner, A. C. (2007). Les classes sociales dans la mondialisation. Paris: La Découverte, Collection Repères.

Weenink, D. (2008). Cosmopolitanism as a form of capital: Parents preparing their children for a globalizing world. Sociology, 42(6), 1089-1106. 